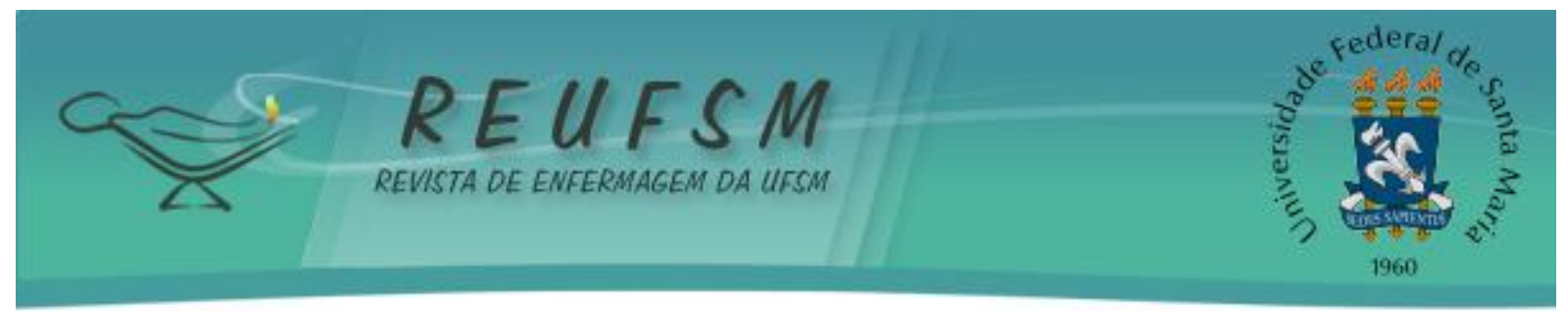

ARTIGO ORIGINAL

\title{
PROFISSIONAIS DE SAÚDE E O PROGRAMA DE CONTROLE DO CÂNCER DO COLO UTERINO E MAMA
}

HEALTH PROFESSIONALS AND CERVIC AND BREAST CANCER CONTROL PROGRAM

PROFESIONALES DE LA SALUD Y EL PROGRAMA DE CONTROL DEL CÁNCER DE CUELLO UTERINO Y DE MAMA

\author{
Maria Carla Vieira Pinho ${ }^{1}$ \\ Denise Albieri Jodas ${ }^{2}$ \\ Maria José Scochi ${ }^{3}$
}

RESUMO: Objetivo: compreender a percepção dos profissionais de saúde em relação ao Programa de Controle e Prevenção do Câncer de Colo de Útero e Mama. Método: estudo avaliativo com 15 trabalhadores de saúde. Utilizou-se um roteiro de entrevistas com perguntas fechadas. Resultados: nas unidades investigadas, pode ser verificado que a cobertura maior ou menor de exames citopatológicos não foi influenciada pela adequação da estrutura física para a coleta do exame preventivo de câncer ginecológico. Já a capacitação e o envolvimento de todos os profissionais lotados na unidade, a divulgação do programa e a rotina com que a mulher realiza anualmente o exame influenciaram em maior cobertura. Considerações: é essencial incluir na formação profissional instrumentos de avaliação da efetividade das ações e melhor compreensão da importância da atenção primária na qualidade de vida das mulheres.

Descritores: Avaliação em saúde; Saúde da mulher; Atenção primaria à saúde; Saúde da família.

ABSTRACT: Objective: to understand the perception of the health professionals on the Cervic and Breast Cancer Control Program. Method: descriptive study with 15 health professionals. A guideline with closed questions was used to collect the data. Results: it could be observed that the higher and the lower covering of cytopathological exams don't seem to be influenced by adaptation of the physical structure. The way of spreading in the program at its own unit, the involvement of all the professionals booked up the unit, the routine in which the woman accomplish her yearly exam, among others facts, shows to influence the high covering. Considerations: it is essential include in the professional formation instruments of evaluation of the effectiveness of their actions and better understanding of the importance of the primary health care in the quality of life of women.

Descriptors: Health evaluation; Women's health; Primary health care; Family health.

RESUMEN: Objetivo: investigar la percepción de los profesionales de la salud en relación al Programa de Control y Prevención del Cáncer de Cuello Uterino y de Mama. Método: estudio evaluativo, con 15 trabajadores de la salud. Se utilizó un instrumento con preguntas cerradas. Resultados: en las unidades investigadas, se puede verificar que la cobertura de mayor o menor de exámenes de citopatología no fue influenciada por la adecuación de la estructura física para la recogida de la prevención del cáncer ginecológico. Ya, la formación

\footnotetext{
${ }^{1}$ Enfermeira. Mestre em Enfermagem pela Universidade Estadual de Maringá. Docente do Departamento de Enfermagem do Centro Universitário das Faculdades Metropolitanas Unidas (FMU). São Paulo, SP, Brasil. E-mail: mariacarlap@uol.com.br

${ }^{2}$ Enfermeira. Mestre em Enfermagem pela Universidade Estadual de Maringá. Docente do Curso Técnico em Enfermagem do Instituto Federal do Paraná, Campus Londrina. Londrina, PR, Brasil. E-mail: denisealbieri@yahoo.com.br

${ }^{3}$ Doutora em Enfermagem. Docente do Departamento de Enfermagem da Universidade Estadual de Maringá. Maringá, PR, Brasil. E-mail: mjscochi@uem.br
} 


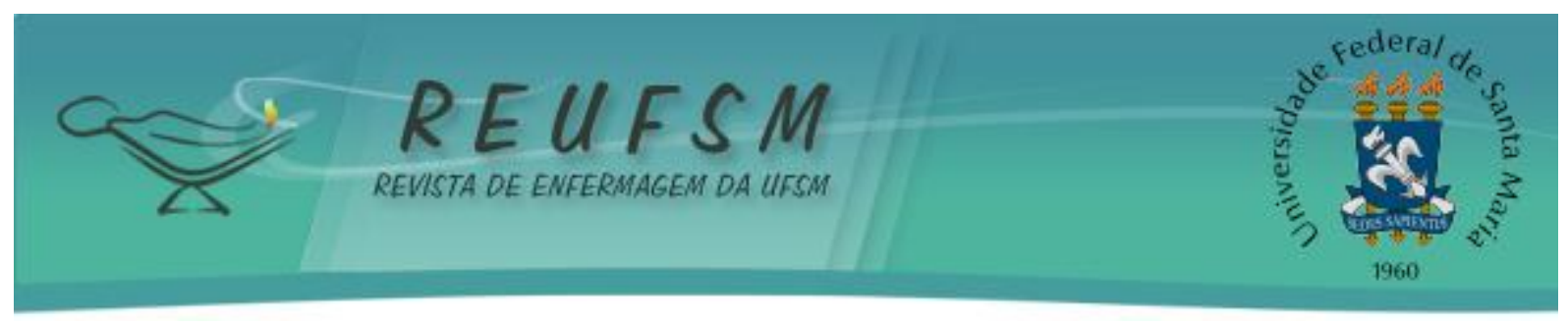

y la participación de los profesionales de la unidad, la divulgación del programa y la rutina que las mujeres realizan la prevención anual influencia de una mayor cobertura. Consideraciones finales: es fundamental incluir herramientas de formación profesional para evaluar la eficacia de las acciones y la comprensión de la importancia de la atención primaria sobre la calidad de vida de las mujeres.

Descriptores: Evaluación en salud; Salud de la mujer; Atención primaria de salud; Salud de la família.

\section{INTRODUÇÃO}

No Brasil, a ocorrência do câncer da mama continua a apresentar uma tendência de crescimento. De acordo com o Instituto Nacional de Câncer, o número de casos novos de câncer de mama feminina esperados para o Brasil em 2012 será de 52.680, com um risco estimado de 52,5 casos a cada 100 mil mulheres. ${ }^{1}$

Quanto ao câncer do colo do útero, estima-se para 2012 um total de 17.540 casos, representando uma incidência de, aproximadamente, 18 casos para cada 100 mil mulheres. Apesar das ações de prevenção e detecção precoce, as taxas de incidência e mortalidade têm-se mantido praticamente inalteradas ao longo dos anos, apresentando-se muito elevadas se comparadas aos países desenvolvidos. ${ }^{1}$

No Brasil, o Ministério da Saúde, com o objetivo de implementar ações de controle para o câncer de colo do útero, desenvolveu em 1997 um projeto piloto em seis localidades - Curitiba, Brasília, Recife, Rio de Janeiro, Belém e no Estado de Sergipe. Em 1998, com a introdução do Sistema de Informações de Controle do Câncer do Colo do Útero (SISCOLO) este projeto foi intensificado e em 1999/2000 foram criadas coordenações estaduais do Programa Viva Mulher, que neste início priorizava o câncer de colo do útero em relação aos outros tipos de câncer. ${ }^{2}$

Em 2004, um processo de avaliação identificou a necessidade de revisão da estrutura e das estratégias do Programa Viva Mulher, de forma a se construir novos meios que permitissem alcançar os objetivos preconizados pelo Programa. Tais constatações motivaram a construção de um Plano de Ação para o Controle do Câncer de Mama e do Colo do Útero no Brasil 2005-2007. ${ }^{3}$

A melhoria da qualidade dos testes diagnósticos, da informação e do preenchimento dos atestados de óbito pode estar influenciando o aumento do número de casos. Em contrapartida, o diagnóstico tardio da doença também dificulta a eficácia do tratamento. Por sua vez, dentre outras causas, o diagnóstico tardio pode estar relacionado com: (1) a dificuldade de acesso da população feminina aos serviços e programas de saúde, (2) a baixa capacitação dos recursos humanos envolvidos na atenção oncológica (principalmente em municípios de pequeno e médio porte), (3) a capacidade do sistema público de saúde de absorver a demanda que chega às unidades de saúde e (4) as dificuldades dos gestores municipais e estaduais em definir e estabelecer um fluxo assistencial orientado por critérios de hierarquização dos diferentes níveis de atenção, que permita o manejo e o encaminhamento adequado de casos suspeitos para investigação em outros níveis do sistema. ${ }^{4}$

A avaliação do desempenho dos programas de controle das neoplasias de mama e do colo do útero deve ser feita por meio de indicadores de qualidade. A tríade da avaliação aborda três aspectos: estrutura, processo e resultado. Estrutura refere-se aos insumos, organização dos serviços, processo, ao modo como o sistema funciona, e resultado ao impacto causado pelo serviço prestado. É uma proposta flexível, porém as etapas se interligam e permitem que cada um as use de acordo com as suas necessidades. Nessa perspectiva, a estrutura corresponde aos recursos humanos (números dos profissionais, distribuição e qualificação), físicos (instrumentos e equipamentos disponíveis, espaço físico) e financeiros (condições organizacionais de financiamento, 


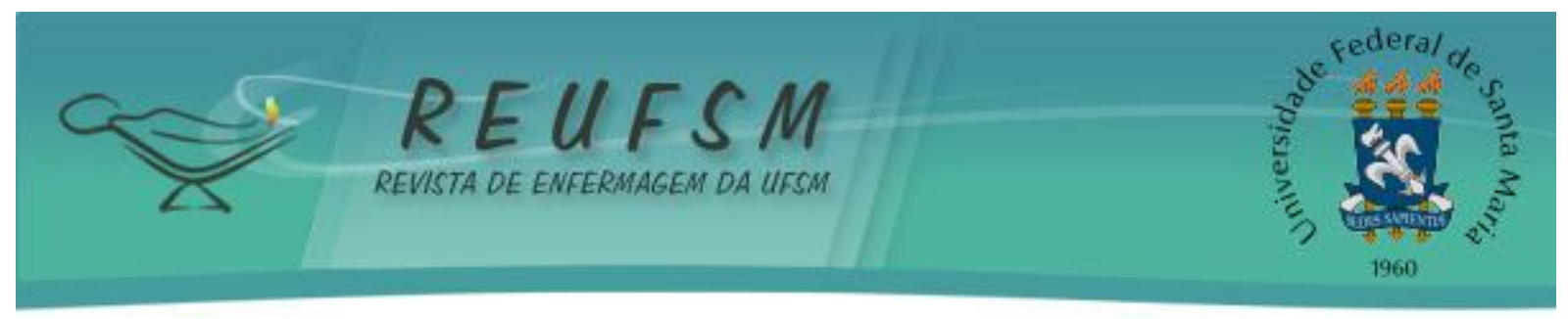

prestação de serviços e fatores de produção). 0 processo diz respeito ao conjunto de atividades desenvolvidas na relação entre profissionais e pacientes. Os resultados são mudanças do estado de saúde do indivíduo que possam ser atribuídas a um cuidado anterior, mudanças relacionadas a conhecimentos e comportamentos e também, a satisfação do usuário diante do cuidado prestado. ${ }^{5}$

No contexto dos serviços de saúde, os profissionais de saúde representam uma importante parcela sobre a qualidade do serviço prestado, visto que estão diretamente ligados e envolvidos no atendimento à saúde do usuário. Um estudo que discute o conhecimento dos saberes e das percepções das mulheres acerca da coleta do citopatológico de colo uterino aproxima os profissionais de saúde à realidade das usuárias do sistema de saúde, conduzindo-os para novas posturas práticas frente ao atendimento a essa parcela da população. ${ }^{6}$ Diante deste contexto, este estudo objetiva compreender a percepção dos profissionais de saúde em relação ao Programa de Controle e Prevenção do Câncer de Colo de Útero e Mama no município de Londrina - PR.

\section{MÉTODO}

O estudo foi realizado no município de Londrina, que apresenta $1650,809 \mathrm{~km}^{2}$ de extensão ${ }^{6}$, encontra-se em uma distância aproximada de $379 \mathrm{~km}$ da capital, Curitiba. Possui população estimada em 497.833 habitantes $^{7}, 1145$ estabelecimentos de saúde e 1628 leitos para internações hospitalares. ${ }^{8}$

A rede pública municipal é composta por 54 Unidades Básicas de Saúde (UBS), sendo 41 na zona urbana, 13 na zona rural, e 36 clínicas odontológicas em UBS além de 01 clínica de especialidade odontológica (CEO), inaugurada no mês de novembro do ano de 2004. O Serviço Municipal de Saúde contempla, ainda, outros serviços de assistência direta à população, como a Maternidade Municipal, o Pronto Atendimento Infantil, os Centros de Atenção Psicossocial, o Serviço de Internação Domiciliar, o Serviço Integrado de Atendimento ao Trauma e Emergência e o Serviço de Atendimento Médico de Urgência.

No município de Londrina as UBS são divididas em: Região Leste, Região Centro, Região Sul, Região Norte, Região Oeste e Região Rural. O número de UBS por região varia de sete, na Região Oeste, a 13 unidades na Rural. Essa variação está de acordo com as características sociodemográficas da cidade. Uma unidade na Região Oeste e outra na Região Centro atende 24 horas, uma na Sul e outra na Norte atendem das $07 \mathrm{hs}$ às $23 \mathrm{~h}$ e as demais unidades funcionam das $07 \mathrm{hs}$ às $19 \mathrm{~h}$. De acordo com o Sistema de Informação da Atenção Básica (SIAB) (2004), todas as unidades totalizam 74,4\% de cobertura da população pelas equipes de saúde da família (ESF).

O SIAB ainda descreve que nessas regiões, a população feminina na faixa etária de 20 a 59 anos oscila de 34.644 mulheres na Região Norte a 6.449 mulheres na Rural. 0 número de exames citopatológicos de colo uterino de 1.904 na Rural até 8.844 na Região Norte. 0 número médio de coletas de material para exames de citologia oncótica (CO) de colo uterino realizados mensalmente variou de 159 na região rural até 737 na Região Norte.

Para o estudo foram selecionadas quatro unidades básicas de saúde, duas de maior e duas de menor cobertura do exame citopatológico, denominadas UBS A, B, C e D. Das unidades eleitas, duas foram da região sul do município de Londrina, uma da região norte e outra da região oeste, três das quais atendem diariamente 12 horas, das $7 \mathrm{~h}$ às $19 \mathrm{~h}$, de segunda à sexta-feira e uma atende por 16 horas, ou seja, das $7 \mathrm{~h}$ às $23 \mathrm{~h}$, inclusive aos sábados, domingos e feriados. A população feminina na faixa etária de 20 a 59 anos, de acordo com o SIAB, variou de 2.210 a 8.254 mulheres e o número de exames 


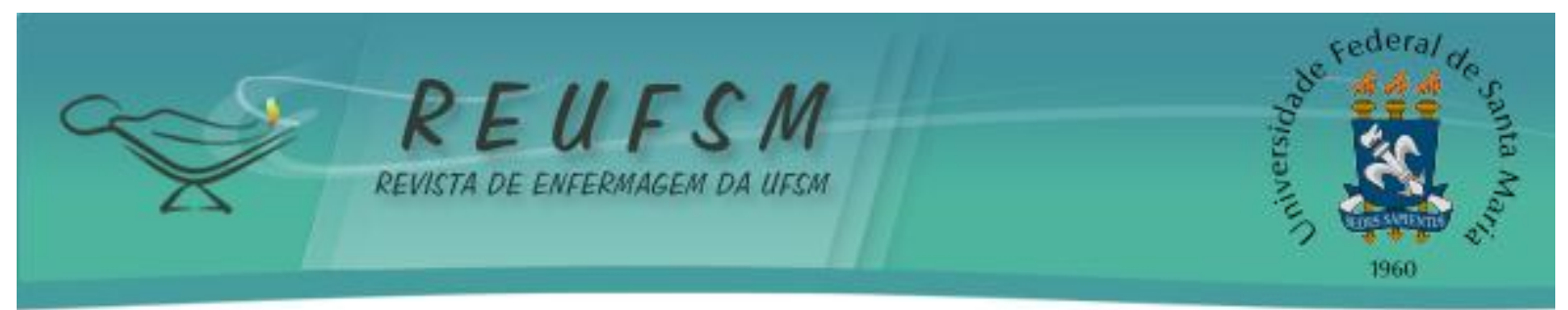

citopatológicos realizados no ano de 2004 variou de 520 a 1.801. 0 índice de cobertura de exames citológicos cérvico-vaginais apresentou variações de 7,16\% a 57,67\%.

Dos 171 trabalhadores existentes nas quatro unidades selecionadas, $15(8,77 \%)$ foram indicados pelos coordenadores como trabalhadores envolvidos diretamente no Programa de Controle do Câncer do Colo do Útero e de Mama, realizando busca ativa, fazendo ações educativas, colhendo o exame citopatológico ou outras atividades relacionadas.

Como instrumento de coleta de dados utilizou-se um roteiro de entrevistas com perguntas fechadas. Esse roteiro, apesar de conter perguntas fechadas, possibilitou exposição de comentários e sugestões sobre o tema. As perguntas abordaram questões que envolviam a rotina de atendimento às mulheres, a realização de ações educativas, o agendamento para exame de citologia oncótica, a identificação das mulheres de risco da sua área de abrangência, estrutura física e comentários de avaliação do programa.

A organização dos dados aconteceu em formato de tabelas de frequência ou ausência de acontecimentos (indicadores) com o estabelecimento das inferências nas associações verificadas.

Este projeto foi submetido à apreciação do Comitê de Ética em Pesquisa, estabelecido pela Universidade Estadual de Maringá, conforme preconiza a Resolução 196/96 do Conselho Nacional de Saúde, tendo sido aprovado sob o parecer 029/2005.

\section{RESULTADOS E DISCUSSÃO}

Dos 15 trabalhadores indicados, seis eram enfermeiros, quatro auxiliares de enfermagem, quatro médicos e um agente comunitário de saúde (ACS), com idade variada entre 31 e 57 anos. Dentre os profissionais de nível superior (enfermeiros e médicos) apenas um referiu não ter curso de pós-graduação. Os auxiliares de enfermagem e ACS relataram ter concluído o Ensino Médio.

Nas unidades de maior cobertura, os entrevistados compreendem que os profissionais que realizam os exames citopatológicos estão capacitados. Já em relação às unidades de menor cobertura não houve esse consenso; dois dos entrevistados julgaram que os profissionais eram parcialmente capacitados para realização desse exame, um deles referiu-se a si mesmo, dizendo que ficava inseguro em algumas coletas e outro expressou a necessidade de um novo treinamento.

O Ministério da Saúde orienta que dois profissionais da saúde podem realizar a coleta do material para o citopatológico, estabelecendo que o médico o faça durante avaliação clínico-ginecológica completa, e o enfermeiro, desde que treinado, em coletas regulares, quando esta ação contribuir para uma maior abrangência da prevenção. No entanto, o protocolo enfatiza que o profissional de saúde deve assegurar estar preparado para a realização do exame. ${ }^{9}$

Houve discordância quanto ao tempo de ocorrência da última capacitação profissional entre os entrevistados. Ou seja, seis deles não souberam informar quando houve a última capacitação para a realização da prevenção do câncer ginecológico, oito disseram que essa capacitação acontecera há três ou quatro anos, quando foi implantado o Programa Saúde da Família (PSF) no município, e um relatou que a última capacitação ocorrera há menos de dois anos.

Dentre as atribuições dos profissionais de saúde no Programa de Controle de Câncer de Colo de Útero e Mama, estão descritas a realização de atividades de educação permanente junto aos demais profissionais da equipe ${ }^{3}$, destacando que o médico da saúde da família deve orientar o enfermeiro na correta realização da coleta de material para o exame citopatológico do colo uterino. ${ }^{9}$ 


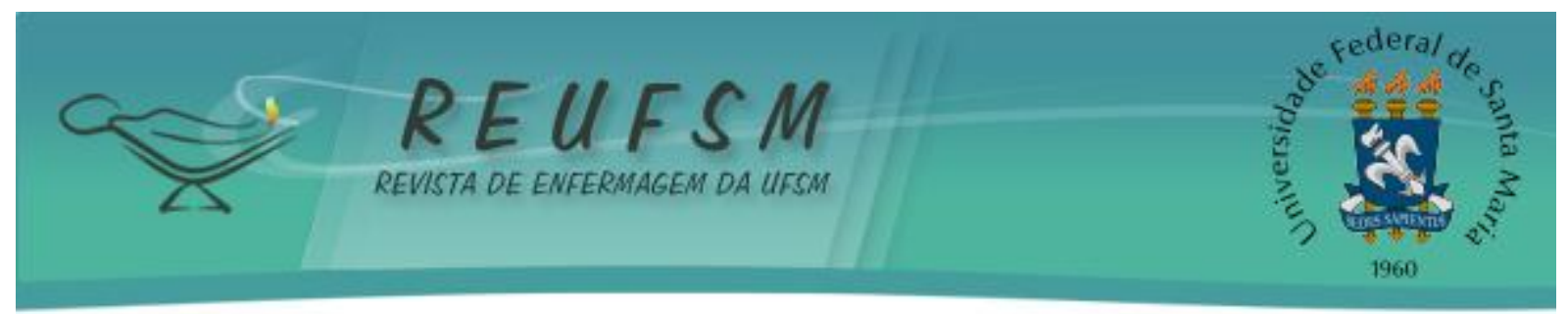

O Código de Ética dos profissionais de enfermagem, por meio da Resolução COFEN-311/2007, vem ao encontro desta assertiva quando destaca a responsabilidade profissional em manter-se atualizado em relação aos conhecimentos técnico-cientificos para benefício da clientela. ${ }^{10}$

Dos 15 profissionais, nove fazem parte das ESF. Destes, cinco são enfermeiras, dois auxiliares de enfermagem, um ACS e um médico. Vale ressaltar que o médico da ESF é ginecologista atuante em uma UBS de maior cobertura, podendo ser um fator contribuinte para a cobertura atingida. Os outros médicos entrevistados também são ginecologistas, porém não atuam na ESF. Nenhum outro médico clínico geral, contratado para a ESF foi citado como participante efetivo do programa de prevenção das neoplasias.

Os profissionais envolvidos no Programa revelaram que não há participação dos médicos da ESF na coleta de citologia oncótica (CO), demandando esta atividade exclusivamente para o enfermeiro, descartando a oportunidade de avaliar completamente esta mulher em consulta. Das enfermeiras entrevistadas, 83,3\% integrava uma ESF, o que demonstra envolvimento desses profissionais nas atividades preventivas.

As respostas mencionadas pelos profissionais sobre a existência de rotinas de atendimento na UBS, a adequação da estrutura física para a coleta do exame preventivo de câncer ginecológico e a utilização de registros para monitoramento das mulheres mostraram que não há diferencial entre as unidades. Isso possibilita afirmar que não são esses fatores que favorecem a realização de mais ou menos exames citopatológicos (TABELA 1).

Tabela 1 - Aspectos sobre estrutura e funcionamento abordados na entrevista com os profissionais que atuam no Programa de Controle do Câncer do Colo do Útero e de Mama em Londrina- PR, 2005.

\begin{tabular}{|c|c|c|c|c|c|}
\hline \multirow[t]{2}{*}{ Aspectos abordados } & \multirow{2}{*}{$\begin{array}{l}\text { Respostas } \\
\text { referidas }\end{array}$} & \multicolumn{2}{|c|}{$\begin{array}{l}\text { UBS de maior } \\
\text { cobertura }\end{array}$} & \multicolumn{2}{|c|}{$\begin{array}{l}\text { UBS de menor } \\
\text { cobertura }\end{array}$} \\
\hline & & $\mathrm{N}$ & $\%$ & $\mathrm{~N}$ & $\%$ \\
\hline \multirow{2}{*}{$\begin{array}{l}\text { Existência de Rotina de } \\
\text { Atendimento à Mulher }\end{array}$} & Sim & 10 & $100 \%$ & 05 & $100 \%$ \\
\hline & Não & & - & - & - \\
\hline \multirow{3}{*}{$\begin{array}{l}\text { Adequação da estrutura } \\
\text { física para coleta de C.O. }\end{array}$} & Total & 05 & $50 \%$ & 02 & $40 \%$ \\
\hline & Parcial & 05 & $50 \%$ & 03 & $60 \%$ \\
\hline & Não adequada & - & - & - & - \\
\hline \multirow{3}{*}{$\begin{array}{l}\text { Adequação dos materiais } \\
\text { disponíveis }\end{array}$} & Total & 07 & $70 \%$ & 04 & $80 \%$ \\
\hline & Parcial & 02 & $20 \%$ & - & - \\
\hline & Não adequado & 01 & $10 \%$ & 01 & $20 \%$ \\
\hline \multirow{3}{*}{$\begin{array}{l}\text { Existência de registros na } \\
\text { UBS }\end{array}$} & Sim & 09 & $90 \%$ & 05 & $100 \%$ \\
\hline & Não & 01 & $10 \%$ & - & - \\
\hline & Não sabe & - & - & - & - \\
\hline
\end{tabular}

Todos os profissionais relataram existir rotinas de atendimento à mulher em relação ao Programa de Prevenção, apresentando demanda por procura espontânea, busca ativa ou acompanhamento por meio de agendamentos para consultas médicas e de enfermagem. Em uma das UBS de maior cobertura, era garantido o agendamento para coleta de citologia oncótica com horários alternativos, inclusive finais de semana e dias de campanha de vacinação.

Os resultados apresentados contemplam o preconizado no protocolo de atendimento à mulher, nas ações de busca ativa para rastreamento de mulheres de sua micro área para detecção precoce dos cânceres do colo do útero e de mama e seguimento das mulheres que apresentam resultado do exame preventivo alterado, amostras insatisfatórias e sem anormalidades para o acompanhamento periódico. ${ }^{3}$ 


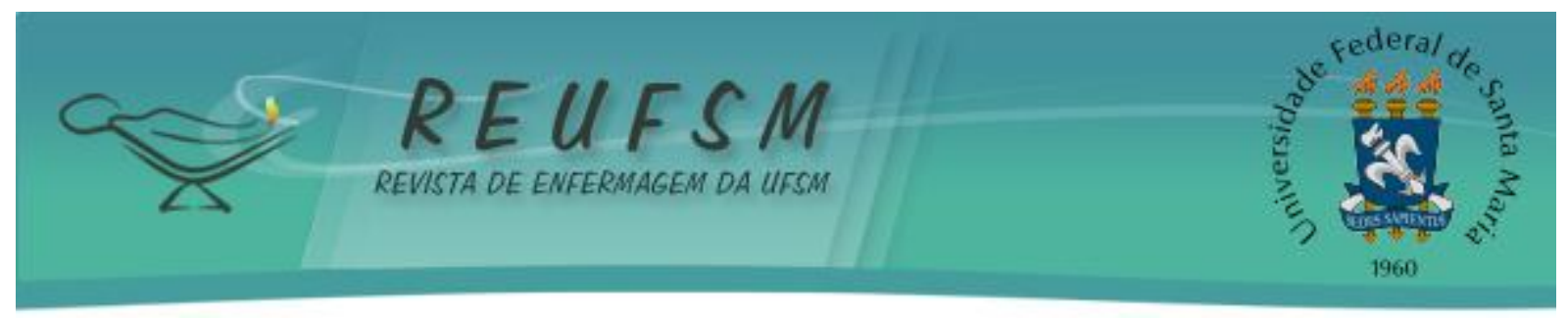

Nenhum profissional considerou a estrutura física inadequada para a realização do exame preventivo, sete consideraram a estrutura física totalmente adequada, sendo que os entrevistados destacaram a importância da privacidade para a coleta do exame e fizeram sugestões quanto à manutenção do ambiente a fim de proporcionar o relaxamento da mulher por meio de música ambiente e a disponibilização de um espelho; oito trabalhadores a consideraram parcialmente adequada, alegando que a maca é estreita para pacientes obesas, que a falta de espelho dificulta na orientação do auto-exame das mamas e a falta de sala para a coleta em determinados horários devido ao seu uso por outros profissionais.

Avaliando alguns aspectos da estrutura física e organizacional do programa, 11 profissionais referiram que os materiais disponíveis eram adequados, atribuindo a existência de kits descartáveis, compostos por escovinha, espátula de Ayre e lâmina, e por haver regularidade no abastecimento desses materiais. Um profissional considerou parcialmente adequado por não ter espéculo descartável (instrumento introduzido no canal vaginal para visualização do colo); outro relatou adequação total dos materiais justamente por não ter esse instrumento descartável, complementando que certa vez o mesmo foi disponibilizado, mas apresentava ranhuras na extremidade dificultando sua introdução no canal vaginal e trazendo desconforto para a mulher.

0 relato sobre o sistema de referência e contrarreferência apareceu em dez falas dos entrevistados, sendo que quatro apontaram que a rotina para a mulher com exames alterados era o encaminhamento para níveis secundário e terciário de atenção. Uma profissional verbalizou não conhecer serviços de referência e nem o que seria contrarreferência, no entanto relatou acompanhar uma usuária com resultado positivo ao serviço de referência, já que na ocasião nenhum familiar poderia acompanhá-la.

O sistema de atendimento necessário para executar o Programa de Controle do Câncer do Colo Uterino e Mama se estrutura no formato de rede, operando em níveis de atendimento, sendo que o nível primário de atenção presta ações de promoção à saúde, prevenção de doenças e detecção precoce das neoplasias de colo e mama, o nível secundário atua no diagnóstico e tratamento e o nível terciário complementa o tratamento de lesões cirúrgicas não tratadas no secundário. ${ }^{11}$

Um dos profissionais que apontou a existência de referência e contrarreferência assegurou que atendia as mulheres no serviço de referência, garantindo a entrega da guia de contrarreferência a todas as mulheres. Além disso, acreditava que os outros profissionais daquele serviço também utilizavam esse procedimento.

Um estudo verificou, entre outras abordagens, a existência de referência e contrarreferência ao analisarem o perfil dos consórcios intermunicipais de saúde do Paraná, concluindo que este mecanismo administrativo entre serviços é importante em relação à racionalidade e efetividade, e que, frequentemente, é valorizado em discursos, mas é pouco e mal praticado. ${ }^{12}$

Para a efetiva implementação do sistema de referência e contrarreferência devese pensar na articulação de uma proposta entre as instituições envolvidas, com comprometimento dos indivíduos que estão executando e usufruindo esse mecanismo.

Aos profissionais cabe a responsabilidade de utilizar as guias de referência e contrarreferência de forma adequada, com dados completos e com os motivos dos encaminhamentos preenchidos corretamente. Se os limites interinstitucionais existem, é possível incluir a usuária como corresponsável neste processo, informando que a organização do serviço ajudará a resolver, de fato, as suas necessidades de saúde.

Apenas um profissional relatou não saber da existência dos registros realizados na UBS sobre a coleta dos exames preventivos do câncer ginecológico. Os demais (14) que referiram saber dos registros nas unidades especificaram que os mesmos continham data 


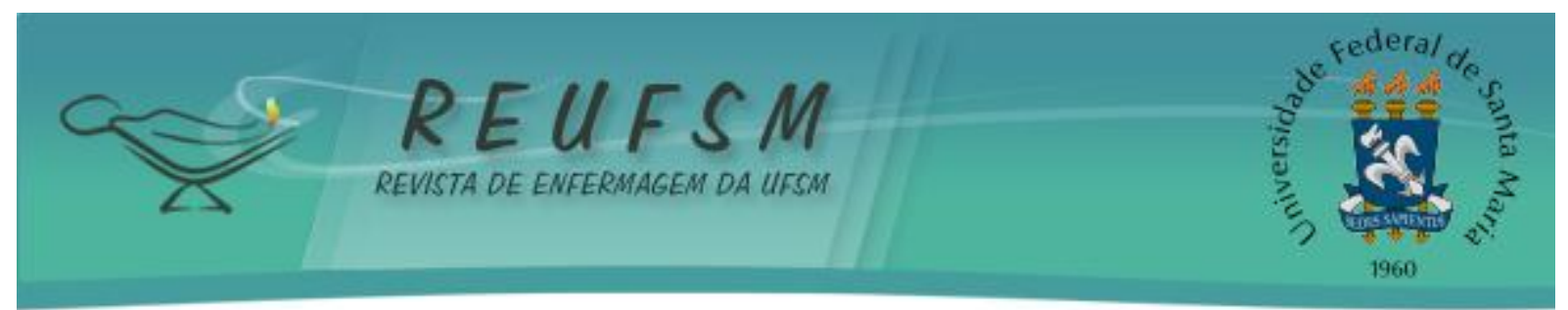

da coleta, nome da usuária, idade, número do prontuário, endereço, telefone e de um espaço para anotação do resultado quando esse retornava do laboratório.

$\mathrm{Na}$ Tabela 2 pode ser observado o conhecimento dos entrevistados sobre a existência de divulgação do Programa de Controle do Câncer do Colo Uterino e Mama em Londrina, ações educativas, possibilidades de agendamento para a realização do exame preventivo do câncer ginecológico, número de mulheres na faixa etária de risco, preconizada pelo Ministério da Saúde, e número médio de coletas de C.O. realizado na unidade em que o profissional atua.

Tabela 2 - Aspectos abordados pelos profissionais entrevistados sobre a divulgação, atividades e informações do Programa de Controle do Câncer do Colo do Útero e de Mama em Londrina-PR, 2005.

\begin{tabular}{|c|c|c|c|c|c|}
\hline \multirow[t]{2}{*}{ Aspectos abordados } & \multirow[t]{2}{*}{ Respostas Referidas } & \multicolumn{2}{|c|}{$\begin{array}{l}\text { UBS de maior } \\
\text { cobertura }\end{array}$} & \multicolumn{2}{|c|}{$\begin{array}{l}\text { UBS de menor } \\
\text { cobertura }\end{array}$} \\
\hline & & $\mathrm{N}$ & $\%$ & $N$ & $\%$ \\
\hline \multirow{3}{*}{$\begin{array}{l}\text { Realização de ação } \\
\text { educativa }\end{array}$} & Sim & 08 & $80 \%$ & 02 & $40 \%$ \\
\hline & Não & 02 & $20 \%$ & 02 & $40 \%$ \\
\hline & Não sabe & - & - & 01 & $20 \%$ \\
\hline \multirow{3}{*}{$\begin{array}{l}\text { Existência de agenda para } \\
\text { coleta do exame } \\
\text { citopatológico }\end{array}$} & Sim & 10 & $100 \%$ & 05 & $100 \%$ \\
\hline & Não & - & - & - & - \\
\hline & Não sabe & - & - & - & - \\
\hline \multirow{2}{*}{$\begin{array}{l}\text { Conhecimento sobre o } \\
\text { numero de mulheres na } \\
\text { faixa etária de risco }\end{array}$} & Sim & 02 & $20 \%$ & - & - \\
\hline & Não & 08 & $80 \%$ & 05 & $100 \%$ \\
\hline \multirow{3}{*}{$\begin{array}{l}\text { Informação sobre média } \\
\text { mensal de exames } \\
\text { citopatológicos }\end{array}$} & Sim & 10 & $100 \%$ & 05 & $100 \%$ \\
\hline & Não & - & - & - & - \\
\hline & Totalmente divulgado & 04 & $40 \%$ & - & - \\
\hline \multirow{3}{*}{$\begin{array}{l}\text { Divulgação do Programa } \\
\text { em Londrina }\end{array}$} & Parcialmente divulgado & 05 & $50 \%$ & 04 & $80 \%$ \\
\hline & Não divulgado & 10 & $10 \%$ & - & - \\
\hline & Não sabe & - & - & 01 & $20 \%$ \\
\hline
\end{tabular}

Dos nove profissionais que relataram ocorrência de divulgação parcial do Programa em Londrina, cinco eram enfermeiros, três auxiliares de enfermagem e um médico. Para dois dos médicos, um auxiliar de enfermagem e um ACS esse Programa foi considerado totalmente divulgado. Uma enfermeira considerou que não existe divulgação referente ao Programa e um médico referiu não saber sobre a divulgação.

Os profissionais, de uma forma geral, expressaram não saber da divulgação do Programa no município, mas tinham como parâmetro a sua UBS de trabalho. Referiram que nas unidades de maior cobertura quem divulgava eram os trabalhadores da unidade, os ACS por meio das visitas domiciliares, e as usuárias mediante comunicação informal.

0 exposto permite inferir que, nas unidades de maior cobertura, a divulgação faz parte do cotidiano de trabalho, está embutida no processo de trabalho, contando-se com o trabalho dos ACS e sensibilização das mulheres por qualquer trabalhador que esteja em contato com elas. Nas unidades de menor cobertura a responsabilização é transmitida à usuária e, embora exista alguma participação da equipe, esta não está incorporada na rotina de atendimentos.

Um profissional considera que "as mulheres não procuram a unidade por não terem conhecimento, não valorizarem o exame e julgá-lo um exame chato". Em uma das unidades de menor cobertura, um profissional questionou a efetividade de cartazes para aumento da cobertura: "em termos de Londrina, pelo percentual de coleta, é 


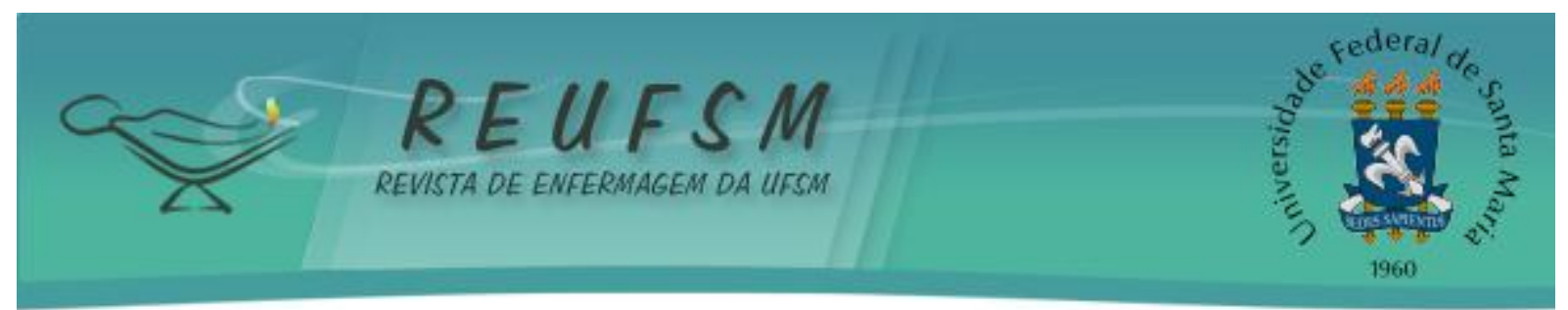

suficiente sim, porque na realidade, independente de ter propaganda elas não vem colher, especialmente às de mais idade", também relata que "com o PSF o pessoal tem incentivado".

Um estudo realizado em Campinas-SP destacou que os fatores associados a não realização do Papanicolau eram ter idade entre 40 e 59 anos, ser preta ou parda e ter até quatro anos de escolaridade. Entre os motivos alegados pelas entrevistadas, que nunca realizaram o Papanicolau, destacavam-se: achar desnecessário $(43,5 \%)$, sentir vergonha $(28,1 \%)$ e $13,7 \%$ por dificuldades relacionadas aos serviços. ${ }^{13}$

Cinco enfermeiros, dois auxiliares de enfermagem e três médicos relataram que são realizadas ações educativas referentes à prevenção do câncer de mama, câncer de colo de útero e também outros temas como Doenças Sexualmente Transmissíveis (DST), Síndrome da Imunodeficiência Adquirida (AIDS) e sexualidade. Uma enfermeira, dois auxiliares de enfermagem e um ACS referiram que não são realizadas ações educativas. Um médico referiu não saber dizer sobre ações educativas relacionadas ao tema.

Em todas as unidades, as ações educativas acontecem, na sua maioria, de forma individual e no consultório. Os profissionais relataram dar orientações, no entanto, não sabem se na sua unidade os outros também o fazem. Apenas uma enfermeira disse fornecer orientações coletivamente às mulheres antes de iniciar a coleta, utilizando linguagem simples, acessível e possibilitando um canal aberto de comunicação entre o profissional e as próprias usuárias, para que exteriorizem e compartilhem as próprias experiências.

A difusão do conhecimento sobre o comportamento epidemiológico das doenças é fator essencial por permitir à comunidade, como um todo, participar de modo ativo no esforço comum voltado à redução dos danos causados à sociedade por certos agravos. 0 conhecimento restrito a um grupo, quando não é socializado, corre sérios riscos de se tornar uma atividade estéril. ${ }^{14}$

Alguns profissionais relataram ser necessário divulgar o Programa, agilizar capacitações, melhorar referências e contrarreferência, implantar protocolo de CO, possibilitar que o auxiliar de enfermagem faça a coleta de material para o exame, haver padronização do período entre uma coleta e outra, esclarecer a realização ou não do exame em gestantes.

Para avaliação do resultado ${ }^{5}$, utilizou-se o índice de cobertura para coleta de exames citopatológicos, sendo que para o ano de 2003 a meta pactuada pelo município em estudo foi maior ou igual a 35\%, a qual, porém, não foi atingida. Para 2004, a meta pactuada foi maior ou igual a 20\%, mas atingiu 19\%; então para 2005 a meta pactuada foi de $19 \%$.

Em relação à Prevenção ao Câncer de Mama em Londrina, no ano de 2003 a meta pactuada foi de até 14,68 óbitos por câncer de mama para 100 mil mulheres e obteve com resultado 13,65 óbitos por 100 mil nesse ano. Para 2004 pactuou-se uma taxa de até 13,65 óbitos/100 mil mulheres, mas a meta não foi atingida, visto que a taxa chegou a 14,69 por 100 mil.

\section{CONSIDERAÇÕES FINAIS}

Dos aspectos abordados relativos à estrutura, processo e resultado, no programa, é possível considerar que as ações de prevenção para o câncer de mama pouco foram referidas pela população estudada, necessitando de outros estudos para investigar o quanto estes profissionais estão capacitados para esta atividade.

Questiona-se, também, o quantitativo de profissionais capacitados para manter este programa de prevenção, visto que os coordenadores locais indicaram apenas 15 trabalhadores, dez das unidades de maior cobertura e cinco de menor cobertura como responsáveis diretos. Será que as unidades de maior cobertura conseguem se aproximar da 


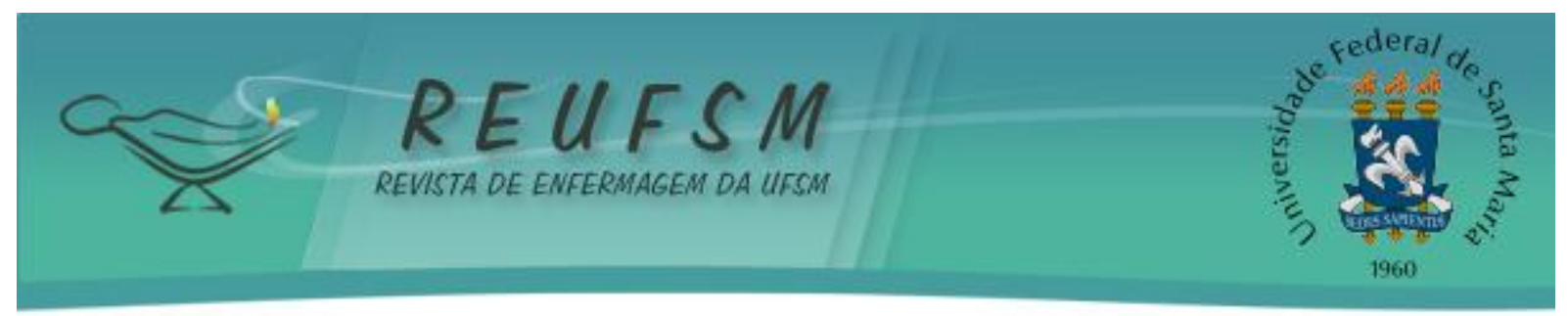

taxa pactuada por possuir um maior número de trabalhadores quando comparado às UBS de menor cobertura ou a questão está a nível organizacional de cada unidade de saúde?

É essencial, também, que cada profissional que atua diretamente com a população usuária do serviço compreenda o quanto o Programa de Controle do Câncer do Colo Uterino e Mama pode refletir na qualidade de vida das mulheres, promovendo saúde e prevenindo doenças.

Acredita-se que estudos desta natureza podem alertar profissionais, gestores e população de que o óbito de uma mulher por câncer de mama ou câncer de colo uterino é evitável e independente do serviço de saúde utilizado, repercute na taxa do município. Isto pode contribuir para repensarem suas práticas profissionais, seu compromisso com os serviços de saúde e, consequentemente, a construção de um sistema de saúde melhor.

\section{REFERENCIAS}

1. Brasil. Ministério da Saúde. Instituto Nacional de Câncer. Estimativa 2012: incidência de câncer no Brasil/Instituto Nacional de Câncer. Rio de Janeiro: INCA; 2011 [internet]. [acesso em 2012 mar 20]. Disponível em http://www.inca.gov.br.

2. Bicalho SM, Aleixo JL. O Programa Viva Mulher: Programa Nacional de Controle do Câncer de Colo uterino e de mama. Rev Mineira Saúde Pública. 2002;1:1-7.

3. Brasil. Secretaria de Atenção à Saúde. Departamento de Atenção Básica. Controle dos cânceres do colo do útero e da mama / Secretaria de Atenção à Saúde, Departamento de Atenção Básica. - Brasília: Ministério da Saúde; 2006.

4. Brasil. Ministério da Saúde. Plano de ação para o controle dos cânceres de colo do útero da mama 2005-2007: diretrizes estratégicas. Brasília; 2005.

5. Donabedian A. The seven pillar of quality. Archives Pathology Laboratory. Medicine. 1990;114:1115-8.

6. Wünsch S, Oliveira SG, Garcia SG, Domingues IB. Coleta de citopatológico de colo uterino: saberes e percepções de mulheres que realizam o exame. Rev Enferm UFSM [internet]. 2011[acesso em 2011 nov 20]; set/dez;1(3):360-8. Disponível em: http://cascavel.ufsm.br/revistas/ojs-2.2.2/index.php/reufsm/article/view/2543/2385

7. Instituto Brasileiro de Geografia e Estatística [internet]. [acesso em 2011 nov 20]. Disponível em http://www.ibge.gov.br.

8. Cadastro Nacional de Estabelecimentos de Saúde [internet]. [acesso em 2011 nov 20]. Disponível em http://cnes.datasus.gov.br.

9. Brasil. Ministério da Saúde. Prevenção e Controle do Câncer de Colo de Útero e Mama. Protocolos de Atenção à Saúde da Mulher; 2008.

10. Conselho Federal de Enfermagem. Resolução n. 311 de 08 de fevereiro de 2007. Dispõe sobre o Código de Ética dos Profissionais de Enfermagem, 2007 [internet]. [acesso em 2011 dez 15]. Disponível em http://site.portalcofen.gov.br/node/4345.

11. Brasil. Ministério da Saúde. Controle do câncer do colo uterino: Programa Nacional de Controle do Câncer de Colo Uterino; 2001.

12. Nicoletto SCS, Cordoni Jr L, Costa NR. Consórcios Intermunicipais de Saúde: o caso do Paraná, Brasil. Cad Saúde Pública. 2005;21(1):29-38. 


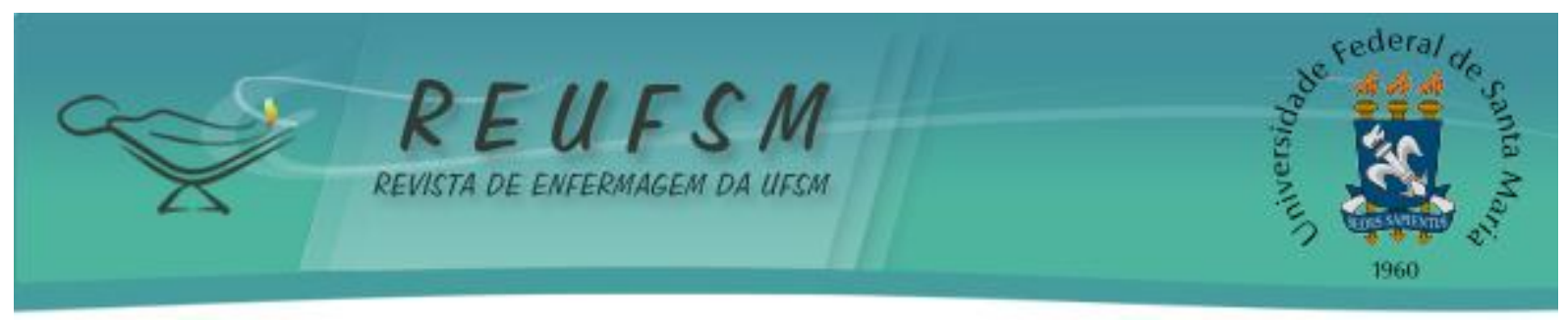

13. Amorim VM, Barros MBA, Carandina L, Goldbaum M. Fatores associados à não realização do exame de Papanicolaou: um estudo de base populacional no Município de Campinas. Cad Saúde Pública. 2006;22(11):2329-38.

14. Secretaria do Estado do Paraná (PR). Boletim Epidemiológico. Curitiba; 2004. n. 20.

Data de recebimento: 05/12/2011

Data de aceite: $21 / 04 / 2012$

Contato com autor responsável: Maria Carla Vieira Pinho

Endereço: Rua Pires da Mota, 647, apto 82 B, São Paulo-SP, Brasil

E-mail: mariacarlap@uol.com.br 